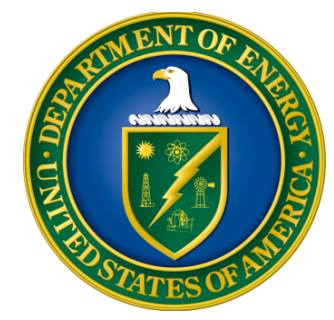

\title{
GENABILITY
}

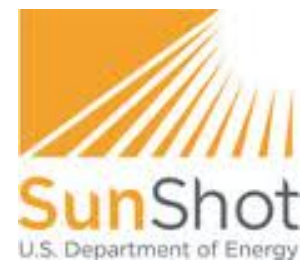

\section{Genability, Inc. \\ Solar Avoided Cost Solution \\ SunShot 6 Final Report}

Award Number:

DE-EE0005843

Principal Investigator:

John Tucker

jtucker@genability.com

(415) 371-0136

Submitted By:

Eric Danziger

edanziger@genability.com

(415) 830-4038 


\section{Table of Contents}

Executive Summary 3

Company Background \& Overview 3

Solar Avoided Cost Solution Overview 3

Baseline Summaries 3

Project Overview 8

Task 1 - Typical Cost 9

Task 2 - Avoided Cost Optimization 13

Task 3 - Solar Provider Module $\quad 15$

$\begin{array}{ll}\text { Deliverables } & 17\end{array}$

D1 - Avoided Cost Simple $\quad 18$

D2 - Avoided Cost Constrained 18

D3 - Avoided Cost Constrained 19

D4 - Launch 20

Product Launch \& Traction 20

Genability Solar Savings Product Launch $\quad 20$

Genability Developer Toolbox Product Launch 20

Media Attention \& Marketing Events $\quad 21$

Appendix I: Features List $\quad 22$ 


\section{Executive Summary \\ Company Background \& Overview}

Genability sells software that accurately calculates solar savings. Practically every solar system installed in the U.S. is sold with the promise that the power it generates will save money compared to the cost of buying the same power from a utility (referred to as "Avoided Cost" or "Solar Savings"). Savings affects everything from educating potential buyers, generating leads, designing economically attractive systems, presenting proposals, converting potentials to customers, servicing systems once live, optimizing rate plans and keeping customers happy with their solar purchase. With Genability's flexible software, we put Solar Savings at the heart of all these steps with low cost and high accuracy.

Today, solar providers and installers use Genability to calculate solar savings during bid preparation. They enter their customers' current electric usage and costs, then project usage and costs both with and without solar. Our calculations rely on our comprehensive rate database and sophisticated rate engine to deliver precise solar savings in milliseconds.

Our current customers have integrated our SunShot 6 solution into their processes including Sunrun, Borrego Solar, SunEdison and NRG. Through June 2013, we have calculated savings for over 200,000 residential proposals (750 mW installed capacity, worth \$3.7 BN) and 300 commercial solar bids (500 GWh solar production modeled). Using this solution, our customers have reduced bid preparation soft costs by $30 \%$.

\section{Solar Avoided Cost Solution Overview}

Genability's SunShot 6 project, "Solar Avoided Cost Solution", helps solar installers \& providers streamline and optimize the solar transaction process.

Before the start of the SunShot project, Genability heard from solar developers and installers that market identification, quote generation and bid preparation were extremely time consuming and inaccurate. Much of this work was done manually and with generic and bad estimates. Solar providers were looking for an accurate, automated tool to prepare better solar bids with a faster more precise Solar Savings. This was the primary goal of our SunShot 6 project.

Genability developed a web application for solar providers to manage their lead-to-close process, and a suite of tools that all solar stakeholders (hosts, installers and financiers) can use to maximize Solar Savings and minimize time spent on the sales process. The Solar Avoided Cost Solution, a software-as-a-service ("SaaS") product, is easy-to-use, easy-to integrate, modular and extremely cost effective.

\section{Baseline Summaries}

Prior to the start of the SunShot 6 project, Genability spent the previous 15 months modeling all of the retail electric rates in the U.S. From the vantage point of tariff structure expertise, Genability was qualified to both define the most precise avoided cost for any project and also 
to orchestrate communication and data flow between relevant parties. We had the electricity rate database and the technology to help other energy suppliers and distributors calculate costs. We supplied this rate data and technology to a number of industries including connected home, connected building, energy management providers, as well as solar installers and developers.

With funding from the Department of Energy and the SunShot Initiative, Genability added significant capabilities to our tools and technology to help solar installers and providers save time and money during the proposal and bid preparation process. Specifically, we developed the following capabilities during the SunShot Project that streamlined and optimized the solar transaction:

- Lead Evaluation (Customer Acquisition - Sales Calls/Site Visit). Armed with little more than the basic details of the building, zip code and (sometimes) billing data, a solar provider has to produce an initial quote. Too little savings and the solar transaction may be not be economically viable; promise too much and the provider may spend the remainder of the transaction attempting to live up to that original promise. The solar provider spends at least 4 hours generating the initial quote, which consists of entering monthly kWh numbers into a tariff model and comparing that with various production curves in search of a combination that delivers sufficient, deliverable savings.

Genability Development: At the click of a button, providers can calculate an optimized Avoided Cost to be included in the Initial Quote using the best representative (if not exact) usage data and highly detailed tariff data.

- System Design (Customer Acquisition - Sales Calls/Site Visit). After the site visit, the installer begins to design the production system. The system design is driven by the desire to maximize solar production within the limits of the customer's current consumption, given the site's constraints. Upon completion, this production model is delivered as an annual-hourly load curve (8760 data) to the Solar Provider.

Genability Development: Designed the production system to maximize Avoided Cost, rather than simple power production to account for the total value. Precisely takes into account net metering constraints.

- Bid Preparation (Customer Acquisition - Bid Preparation). The solar provider receives the production curve, calculates the Host's net usage curve, and then calculates (often manually or imprecisely) the avoided cost of the system. The mechanics of this process vary widely among solar providers, from brittle spreadsheets to homegrown software. Our customers reported it often takes 20 hours to complete. All of them agree that the process involves manipulating large sets of data increasing the opportunity for error, maintaining tariff models that are overly simplified or change frequently, and lots of simplifying assumptions that both reduce precision and add risk.

Genability Development: Fixed this step and drastically slashed manual labor. Increased the accuracy of data inputs and automated the calculation of precise avoided cost and optimal tariff selection.

- $\quad$ Structuring of Payment Terms (Financing \& Contracting - Legal Agreement). Once the system is designed and its avoided cost determined, the solar provider begins to model the financial arrangement. They account for system cost (hardware, installation and permitting), the Host's credit, the financiers expected return on investment, and 
the Avoided Cost to come up with a per kWh price (or lease/financing terms) to propose to both the Host and the Financier. This process that takes 30 hours or more depending on how many iterations it takes to get both the Host and Financier to agree. Payment structures take a long time to design because a) they have to be calculated and b) they have to account for different types of risk while maintaining a rate structure that is easy for the Host to understand and for the Solar Provider to collect. Rates are nearly always very simple, cost per kWh rates and rate escalators (optional) that account for expected power rate inflation.

Genability Development: Made rate/terms modeling easy and flexible for both solar providers and financiers. We support sophisticated rate design to unlock more value, and rapid iteration to reach terms faster.

- Sales Process Coordination (Customer Acquisition - Follow Up, Signing Contract).

Throughout the solar transaction, the most recent status of the solar system needs to be consistently communicated to all the parties involved. Status and collaboration become critical as the transactions nears completion and all parties need to be informed and approve final changes. Over 6 hours is spent simply keeping everyone in the loop.

Genability Development: Automatically coordinated the sales process. Share data, eliminate duplicate entry, save time, and increases the trust of all the parties involved by increasing transparency.

At the start of the project, Genability worked with its Alpha partners to baseline the average time required to deliver a solar proposal. Genability's Solar Avoided Cost Solution aimed to generate savings of greater than 30\%. The summary tables below include the time calculated to perform aspects of the proposal process Before Genability and After Genability. We have included one residential example and one commercial example. Both of these were tested with Alpha partners.

Improvements to Residential Baseline - 47\% Savings

\begin{tabular}{|l|c|c|}
\hline \multicolumn{1}{|c|}{ Task } & Before Genability & After Genability \\
\hline 1. Lead Evaluation & 1 Hour & 0.75 Hour \\
\hline $\begin{array}{l}\text { 2. Sales Meeting \& } \\
\text { Site Assessment }\end{array}$ & 2.75 Hours & 2 Hours \\
\hline $\begin{array}{l}\text { 3. System Sizing \& } \\
\text { Design }\end{array}$ & 3 Hours & 0.5 Hours \\
\hline $\begin{array}{l}\text { 4. Bid Preparation \& } \\
\text { PPA Design }\end{array}$ & 2.25 Hours & 0.25 Hours \\
\hline 5. After Sale & 2.75 Hours & 2.75 Hours \\
\hline Total & 11.75 Hours & 6.25 Hours \\
\hline
\end{tabular}




\section{Residential Baseline Before - 11.75 Hours}

According to our residential customers in June of 2012, the Residential Solar lead-to-sale process took 11.75 hours. Below we document how Genability has improved this process and the resulting time and cost savings realized by the Solar Avoided Cost Solution.

Lead Evaluation (review inbound lead and available tariffs, make initial sales call)

1. Most Likely Tariff automatically assigns inbound leads to their most likely tariff and calculates their current average cost/kWh for electricity (Saves 15 minutes)

Sales Meetings \& Site Assessment (meet with the customer and collect utility bills)

1. Bill Entry Tool allows provider to enter and reconcile utility bills quickly for use in calculations (Saves 30 minutes)

2. Solar Savings Analysis based on the Bill Data and PVWatts Solar Production referenced below can be generated in seconds (Saves 15 minutes)

System Design \& Sizing (design and refine proposed solar production)

1. Model Solar Production in PVWatts for use in savings analysis (Saves 60 minutes).

2. Solar Savings Analysis based on the Bill Data and PVWatts Solar Production can be generated in seconds (Saves 25 minutes).

3. Optimize System Size and Avoided Cost using quick iterative Solar Savings Analysis (Saves 75 minutes).

Bid Preparation \& PPA Design (design payment plan and deliver sales proposal to customer)

1. Finalize Solar Savings for proposed solar installation, including Tariff Optimization (Saves 45 minutes).

2. Calculate Optimal PPA/Lease Rate for specific customers (Saves 30 minutes).

3. SalesForce Solar Savings Analysis Integration generates solar savings for seamless inclusion into the Solar Proposal (Saves 45 minutes).

Residential Baseline After - 6.25 Hours

Soft Cost Savings - $47 \%$ 
Improvements to Commercial Baseline - 38\% Savings

\begin{tabular}{|l|c|c|}
\hline \multicolumn{1}{|c|}{ Task } & Before Genability & After Genability \\
\hline 1. Lead Evaluation & 2.5 Hours & 0.75 Hours \\
\hline $\begin{array}{l}\text { 2. Sales Meeting \& } \\
\text { Site Assessment }\end{array}$ & 3 Hours & 2.5 Hours \\
\hline $\begin{array}{l}\text { 3. System Sizing \& } \\
\text { Design }\end{array}$ & 1.75 Hours & 0.75 Hours \\
\hline $\begin{array}{l}\text { 4. Bid Preparation \& } \\
\text { PPA Design }\end{array}$ & 2.5 Hours & 1 Hour \\
\hline 5. After Sale & 2.75 Hours & 2.75 Hours \\
\hline Total & 12.5 Hours & 7.75 Hours \\
\hline
\end{tabular}

Commercial Baseline Before - 12.5 Hours

According to our commercial customers in June of 2012, the Commercial Solar lead-to-sale process took 13 hours. Below we document how Genability has improved this process and the resulting time and cost savings realized by the Solar Avoided Cost Solution.

Lead Evaluation (review RFP, model sample usage, available tariffs and initial response)

1. Typical Load Profiles for Utility-Region-Building Type combinations allow provider to respond to RFPs with representative usage, rates, and costs (Saves 15 minutes)

2. Integrated PVWatts allows provider to model site-specific (reflects location and typical usage) solar production in less than a minute (Saves 30 minutes).

3. Solar Savings Analysis based on the Usage and PVWatts Solar Production can be generated in seconds (Saves 60 minutes).

Sales Meetings \& Site Assessment (meet with the customers and get utility bills)

1. Bill Entry Tool allows provider to enter and reconcile utility bills quickly for use in calculations (Saves 15 minutes).

2. Solar Savings Analysis based on the Bill Data and PVWatts Solar Production can be generated in seconds (Saves 15 minutes).

System Design \& Sizing (design and refine proposed solar production)

1. Accept the PVSyst Output in its native format for use in calculations (Saves 5 minutes).

2. Solar Savings Analysis based on the Bill Data and PV Watts Solar Production can be generated in seconds (Saves 10 minutes).

3. Optimize System Sizing using Cost Analysis and Factor function (Saves 45 minutes). 
Bid Preparation \& PPA Design (design payment plan and deliver sales proposal to customer)

1. Finalize Solar Savings for proposed solar installation, including Tariff Optimization (Saves 30 minutes).

2. Build Private Tariffs for recording PPA/Lease terms across multiple customers (Saves 30 minutes).

3. Customize PPA Terms for specific customer, including escalation assumptions (Saves 15 minutes).

4. Solar Savings Metrics for easy inclusion into the Solar Proposal (Saves 15 minutes).

Commercial Baseline After - 7.75 Hours

Soft Cost Savings - 38\%

\section{Project Overview}

The core objectives of this project were two separate but integrated products, collectively providing game-changing Avoided Cost capabilities.

- The first was a kit of avoided cost tools and data that any solar provider can use a-lacarte or as a whole. It's open and easily accessible nature allows the rapid and accurate calculation of avoided cost in whatever context and software that make sense ("Typical and Avoided Cost Tools"). This kit includes a dataset of typical energy rates, costs and usage that can be used for solar prospecting, lead generation and any situation where data about an opportunity is missing or imperfect.

- The second is a web application and related APIs specifically built for solar providers to radically streamline their lead-to-sale process ("Solar Provider Module"). The typical and Avoided Cost tools are built directly into this, and allow for solar providers to track their opportunities, collaborate with their installers and financiers, and close more sales faster. 
The screenshot below is a Cost Analysis calculation from a California supermarket pre-solar and after-solar. Using our Solar Avoided Cost Solution, an installer was able to upload customer usage data, upload solar production data from popular 3rd party tools and model the Before Solar \& After Solar Utility Avoided Costs.



Below is a summary of each Task in the SunShot 6 project. See Appendix I for a full features list.

\section{Task 1 - Typical Cost}

When specific site and opportunity data is unknown, sparse or incorrect, typical data is highly valuable. Our objective with Task 1 was to create the best database of typical rate, usage and cost data for the solar industry, and to make it easy to use. The complete dataset of typical data includes coverage for the entire U.S., as well as parameters to filter by location, building type, vintage and area. 
Genability also provided a wide array of tools to access and use this typical data. These include i) an API to integrate into any software application, ii) files for download, iii) layers for embedding in maps, and iv) UI widgets to easily plug into web and mobile apps. Typical data is also available for users of Genability Explorer.

\section{Task 1 consisted of 4 subtasks:}

\section{Subtask 1 - Typical Cost Engine \& Database}

Genability built an engine that generates and stores Typical Rate (price), Usage (consumption \& demand), and Cost (amount paid) data, including information on its variability. This used Genability's existing Tariff database and its existing Rate Engine, but required a new set of technologies and data, which were designed and implemented as part of this task. We started by generating Typical data for each major Tariff in California. We then built a usage generating model using DOE-22, and validated its output using data from the Residential Consumption Energy Survey ("RECS"), the Commercial Building Energy Consumption Survey ("CBECS"), the California Commercial End-Use Survey ("CEUS"), and other available data sources. The API generated 15 minute interval rates, rate variability (based on tiers, billing demand and other rate factors). The API also calculated energy costs using typical usage data, in 15 minute intervals, to give the cost of each 15 minutes. Again, these values will have a measure of variability. Once the initial engine was built and queried, Genability analyzed the results, tuned assumptions and inputs and expanded the coverage to include IL and NY. Historical bills are a common way Solar Providers and Installers benchmark customer costs. We built a UI for easily entering these, and a "bill solver" that backs into consumption and demand interval data by combining information on the bill, typical usage data for disaggregation and our rate engine (Dynamic Usage Data). Analysis of demographic data also informed and tuned the mix of usage and tariffs. As the project progressed, our Beta Testers did additional analysis and tuning of the data and methodology. We also expanded geographical coverage to the entire U.S. in month 11. Methodology and accuracy should stabilized in month 9.

The map below from Genability Explorer highlights the residential Typicals added during the SunShot project. Users can select different building types from the left hand menu.

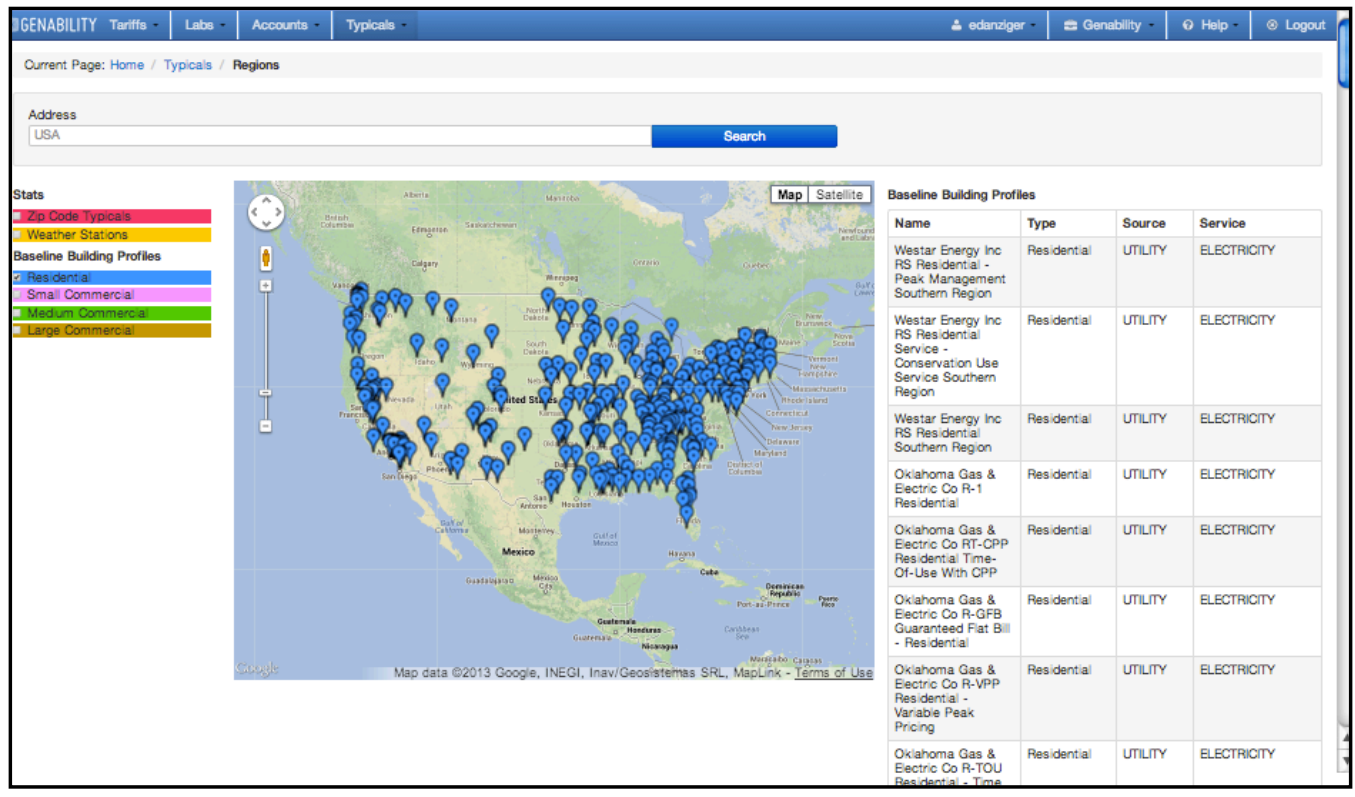


Subtask 2 - Typical Cost APIs \& Downloads

The previous task built the engine and data, and this task made those capabilities available to other software systems and tools (i.e. via new APIs and via data file download). Our customers' own in-house software, 3rd party mobile and web apps, and industry software are able to access our servers and integrate this functionality seamlessly alongside their own. We started by integrating with private alpha partners and also those using Genability Explorer. These systems can query Typical Cost by location (zip code, city, state, latitude-longitude, etc.), by class of customer (residential, commercial, etc), and by other cost/usage driving factors (class of business, square-feet, etc). Typical Cost data is returnable in 15-minute, hourly, daily, monthly, or yearly increments. In Month 5, the APIs were enhanced to support using utility bill data to refine the estimate of usage data (henceforth "Bill Solve"). Bill Solve generates a Dynamic Usage Curve based on the best matching typical usage adjusted using the monthly costs or usage data available on the bill. The first version supported total bill costs, and was then upgraded to handle line item cost adjustments (such as demand) and handle more complex rates (such as tiered pricing). In month 6 , the structure of the data coming from the API was stabilized (little changes after this point). We anticipated that this data would be of use to prospecting and Geographical Information Systems (GIS) and mapping apps, so we supported common GIS formats (GeoJSON and KML). We also allowed downloading populations of the data in CSV format for use in spreadsheets since many databases can easily import this format.

\section{Subtask 3 - Typical Cost User Interface \& Widgets}

This task developed the user interfaces for viewing and interacting with the Typical Cost data, both within our Explorer software, and in 3rd party apps. This started with Wire-framing and included iterative prototyping. A graphical visualization of the Typical Cost data was developed where the user is able to see rates, cost and usage in tabular, chart and summary info-graphic format. This was first implemented for a particular tariff, then for region and class of customer etc. We also "widgetized" (meaning the construction of code that can be copied and pasted into a websites' structure and provide immediate use of our tool) for easy inclusion on a customers' website. The data lends itself to geographical representation too, so implemented a map viewer in Genability Explorer, and made Typical Cost data available as layers (note that via the API these layers were included in 3rd party mapping tools such as Google Earth and customer map apps).

\section{Subtask 4 - Usage \& Demographic Data}

This task involved the collection, analysis, modeling and refinement of the key input and assumption data that drove the calculation of Typical Costs. Typical electricity usage is a key determinant of what it typically costs, so it's important to get the usage numbers accurate. Our approach was to start with known samples of usage data, construct an engine to generate modeled usage data, compare the two, and use the comparison to refine the engine. Our starting samples were RECS, CBECS, CEUS and Utility data for California. Our engine was a hybrid of our own logic and the DOE-2 energy usage software. Energy usage is dependent on type and age of building, function, climate, occupancy and other factors. This subtask tested and refined which variables are most important with respect to typical costs, and integrated these into our engine. We cross checked our data against US Energy Information Administration (EIA) state and utility average cost data, as well as Federal Energy Regulatory Commission (FERC) Form 1 tariff customer count data to determine the likelihood that a customer is on a particular tariff, and also checked that when we sum up our costs across all tariffs, they match aggregate numbers filed by utilities with the FERC. We wanted our 
methodology to be informed by the data, and ratified by our advisor partners, which is why we made it available through APIs and UIs.

WhatIfSolar.com shows graphical illustration of "likely tariff" capability and net metering considerations (see negative "with solar" figures).






\section{Task 2 - Avoided Cost Optimization}

The objective of Task 2 - Avoided Cost Optimization was easy, accurate Avoided Cost calculations. The avoided cost engine needed to be able to take a solar production curve, the best available usage data, accurate rate data for the most suitable tariff, and calculate the pre, post and thus avoided cost of that system. This task built that engine, as well as the tools on top of it to a) pass the required data in, b) augment missing or poor quality data, and c) receive the results in ways that are actionable for that context. Tariff comparison and tariff switching, as well as rapid solar system sizing, allow for finding maximum solar savings.

Customers' historical energy data comes from a variety of formats. We support receiving usage data for utility bills, meter and standard utility report formats, along with Green Button. Historical bills are a common way Solar Providers and Installers benchmark customer costs. We built a UI for easily entering these, and a "bill solver" that figures out consumption and demand by combining information on the bill and typical usage data.

The screenshot below highlights "Creating a Profile" which includes the ways a provider can enter or upload customer usage data into our tools.

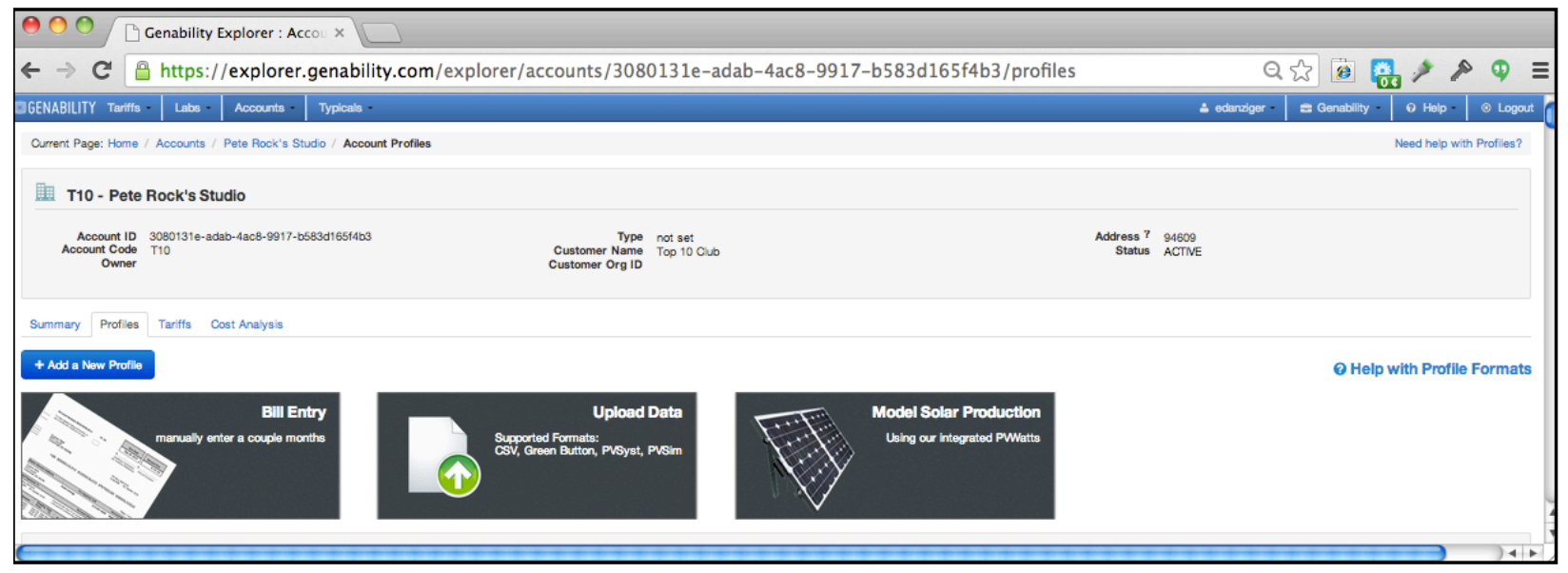

To promote mass adoption, Genability made an API available, as well as some UI widgets for easy embedding in 3rd party apps. This allows avoided cost to be easily plugged into all contexts that make sense (identifying the best leads, designing and sizing the system, negotiating terms, and monitoring the actual avoided costs the system is producing).

\section{Task 2 consisted of 3 subtasks:}

\section{Subtask 1 - Tariff Optimization}

This sub-task was to develop code to analyze and solve for the optimal tariff and configuration of that tariff for a given circumstance (calculation, account or opportunity). This was to identify all applicable tariffs and options to configure those tariffs, determine what each one will cost (including cost variability) and report back on its findings. We wireframed and prototyped the user interface and widget, then implemented the actual algorithm for picking the right tariff). Our alpha customers were able to access tariff optimization via an API call, and then based on their feedback we stabilized the tariff optimization functionality and made it generally available. The User Interface was developed and "widgetized", so that our customers 
with little technical experience could quickly embed the widget in their web pages to show their users which tariffs are available to them, and which one is the optimal tariff. Before the API and Widgets were "stabilized" and the major work was completed on this sub-task, we enhanced the algorithm to also report back the optimal configuration of a tariff.

The screenshot below shows a "What-If Cost Analysis" for a large commercial, facility highlighting tariff comparison.



\section{Subtask 2 - Avoided Cost Engine}

In this subtask we developed the code to calculate energy costs with and without solar production, and thus identify the avoided cost of solar at its marginal price. We started with a straight 1 year calculation for a given account, or a given tariff and input data. Then we implemented a capability to model cost changes over time, for instance to support electricity 
costs rising annually at $2 \%$ for the next 20 years. By default, our calculation use DOE AOE data which is recognized as an objective forecast. However, the engine allows the caller to use his or her own assumptions. We support a variety of different assumptions, such as accelerating rate increases, fluctuating rates, etc., while allowing for different assumptions for different costs. For example, escalating fixed costs (such as meter and interconnection charges) at a different rate than say consumption (kWh), transmission and distribution changes, or billing demand (kW). We also allow PPAs to model their solar production rates. This leverages our rate modeling capability so that the PPA can use any type of rate structure that Utilities provide, from straight kWh rates, to tiering, TOU, indexed and more. We implemented the engine so that solar production rates can be passed in at the time of the calculation or saved and reused.

\section{Subtask 3 - Avoided Cost User Interface}

Starting with wire-frames, we designed and built a user interface that clearly shows the costs offset by solar production. From the initial version, this was enhanced to show cost escalation and when applicable PPA rates. We also made the visualization available as a widget that can be embedded in solar provider, installer or others websites. These UIs will not only report the results, but when in read/write mode, will allow scenario and what-if testings to facilitate typical use-cases for wanting to analyze avoided cost.

\section{Task 3 - Solar Provider Module}

The Solar Provider Module is a set of capabilities specifically designed to drastically reduce the labor and increase the benefit or savings when converting a solar lead into a sale. This module packages together Avoided Cost optimization, typical cost data, and tools that allow solar providers to access lead quality and prepare bids cheaper, quicker, more accurately, and higher volume than is currently possible. Solar providers can track their opportunities, work on bids, and collaborate with installers, financiers and hosts.

Since solar production is typically modeled by the installer in industry standard tools like PVSyst, PVWatts or internally developed tools, Genability integrated these directly into our offerings.

Tracking opportunities and deal flow is also extremely important to providers. To eliminate redundancy and save installers time, Genability developed an integration with a popular CRM tool (Salesforce). Salesforce is the dominant CRM tool among solar providers. Our Salesforce integration allows an installer to generate a quote directly from within Salesforce.

\section{Task 3 consisted of 3 subtasks:}

\section{Subtask 1 - Opportunity Tracking, Sharing \& Workflow}

This sub-task built the tools that facilitate rapid collaboration and automation on solar proposals by their stakeholders. We first implemented opportunity tracking; the ability to capture opportunities, to search and view them, and to track their progress. The system is able to assign access rights and share individual or groups of opportunities with other individuals, organizations and software.

\section{Subtask 2 - Provider Module User Interface}

This task built the user interface that allows Solar Providers and their partners to interact with the Opportunity Tracking, Sharing \& Workflow capabilities, and see the opportunities 
avoided costs and other data. We first wire-framed the Opportunity user interfaces, and iteratively prototyped the screens. We also wireframed the UI for managing PPA rates. The UI for searching, creating, viewing and editing opportunities was implemented next. A rate modeling UI was implemented next. Then, the controls to share opportunities.

\section{Subtask 3 - 3rd Party Tool Integration}

We used a Microsoft Excel Add-in to interact with the APIs in order to a) upload solar production data and usage data, b) download previously uploaded solar production and usage data, and c) download cost, PPA rates and avoided cost data. This tool was available to any party that the opportunity is shared with, but primarily designed for Financiers. We also built the ability for our APIs to accept solar production data from NREL's SAM and PVWatts tools. We leveraged the script and library tools available in these tools to make sending production data to the API and getting cost data from the API as seamless and automated as possible.

Finally, we integrated our tools with popular 3rd party solar modeling tools such as PVSyst and PVWatts. The upload feature and functionality is see below.

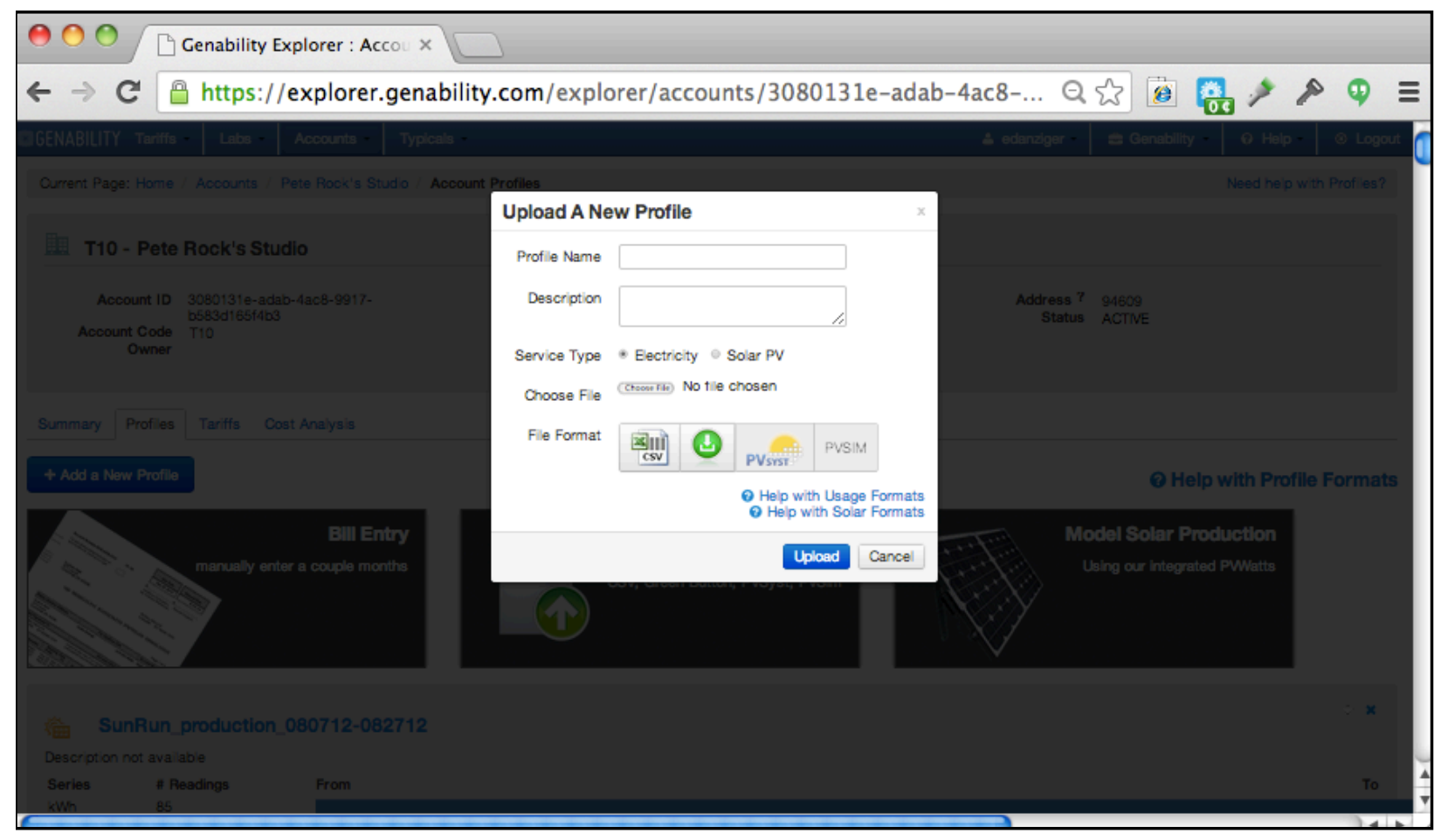




\section{Deliverables}

Genability's Solar Avoided Cost Solution consisted of 5 deliverables over the course of the 12 month project. The table below outlines the key deliverables for each period.

\begin{tabular}{|c|c|}
\hline Deliverable & Criteria \& Deliverable \\
\hline $\begin{array}{l}\text { D0: Baseline } \\
\text { Delivered July 16, } \\
2012\end{array}$ & $\begin{array}{l}\text { What: a) Benchmarked existing solar sales process; captured specific } \\
\text { real world projects to validate with at end of project. b) Review } \\
\text { existing Explorer functionality, GDN documentation site, existing } \\
\text { APIs } \\
\text { How: a) Audited \& collected artifacts for at least } 1 \text { residential and } 1 \\
\text { commercial recently completed solar sale. Documented process } \\
\text { tasks, time per task, wait time between tasks, artifacts used, } \\
\text { numbers calculated etc b) Setup "DOE SunShot" Organization \& } \\
\text { User accounts for all monitors in Production system. Attend demo } \\
\text { webinar. }\end{array}$ \\
\hline $\begin{array}{l}\text { D1: Avoided Cost - } \\
\text { Simple } \\
\text { Delivered Aug. 28, } \\
2012\end{array}$ & $\begin{array}{l}\text { What: a)"Beta" Customers enrolled b) Deliver Alpha Release Version: } \\
\text { Demo-able of avoided cost i.e.. working for typical (static, CA only) or } \\
\text { uploaded profiles. } \\
\text { How: a) Metrics: } 5 \text { customers signed up to be part of Beta, with at } \\
\text { least } 1 \text { actively using our Alpha version b) Experiment: Perform } \\
\text { Alpha version avoided cost tests }\end{array}$ \\
\hline $\begin{array}{l}\text { D2: Avoided Cost - } \\
\text { Constrained } \\
\text { Delivered Dec. 6, } \\
2012\end{array}$ & $\begin{array}{l}\text { What: a) "Beta" Customers using products enough to provide, and } \\
\text { providing, meaningful feedback b) Deliver Beta Release Version. } \\
\text { Better Avoided cost - using dynamic usage profiles, and considering } \\
\text { net metering constraints } \\
\text { How: a) Metrics: } 3 \text { beta customers with at least } 10 \text { accounts each, } \\
\text { plus } 3 \text { beta customers with at least 1,000 API calls each, plus } 1 \\
\text { "Beta" customer using us in their "production" system or process b) } \\
\text { Experiment: Perform Beta version avoided cost tests }\end{array}$ \\
\hline $\begin{array}{l}\text { D3: Avoided Cost - } \\
\text { Optimized } \\
\text { Delivered Feb. 22, } \\
2013\end{array}$ & $\begin{array}{l}\text { What: a) Functionality providing commercially viable value b) Deliver } \\
\text { v0.8 Release Version. Sophisticated avoided cost including PPA } \\
\text { rates, full solar state coverage, and "Beta"-level opportunity } \\
\text { management } \\
\text { How: a) Metrics: } 6 \text { "beta" customers with at least } 20 \text { accounts, plus } \\
\text { 50,000 accumulated avoided cost calculations (excluding genability), } \\
\text { b) Experiment: Perform } 0.8 \text { version avoided cost and opportunity } \\
\text { management tests }\end{array}$ \\
\hline
\end{tabular}




\begin{tabular}{|l|l|}
\hline \multicolumn{1}{|c|}{ Deliverable } & \multicolumn{1}{c|}{ Criteria \& Deliverable } \\
\hline D4: Launched & $\begin{array}{l}\text { What: a) Support complete Solar sales process, b) Deliver v1.0 } \\
\text { Release Version. Commercially c) commercialization plan }\end{array}$ \\
$\begin{array}{l}\text { Delivered Jun. 6, } \\
\text { How: a) Reproduce the solar deals baselined in DO but using our } \\
\text { tools (including using 3rd party lead \&modeling systems). Record } \\
\text { times \& accuracies. Verify equivalent time and accuracy savings are } \\
\text { >30\% of soft costs. b) Product launch. c) Commercialization Plan } \\
\text { Report }\end{array}$ \\
\hline
\end{tabular}

\section{D1 - Avoided Cost Simple}

As stated in the Deliverable Table above, the goal of the first deliverable for the Avoided Cost Solution was to deliver a minimum viable working version of the Avoided Cost Solution and to secure alpha partners to participate in its further development and refinement.

The basic capabilities supported in "D1 Avoided Cost - Simple" were:

1. Calculating the Avoided Cost of Solar based on: 1.1. Baseline (typical) usage data for California (2011 date range)

1.2. Uploaded Usage Data - CSV, GreenButton or Manually Entered from Bills

1.3. Uploaded Solar Production Data - CSV, or generated by calling NREL PVWatts API

2. Running a 12-month Avoided Cost Calculation for combination of Usage and Solar Production data

3. View and use in calculations Baseline Usage Data that represent typical usage patterns for region and customer type

4. View typical usage, rates and costs associated with Baseline Usage Data

In the Avoided Cost Simple version, the Baselines were limited to California, simple usage categories and the full year of 2011.

During the D1 period, Genability also had solar providers commit to being Beta customers including: SunEdison, NRG Solar, ModSolar, SolarCity, SunPower, RECSolar, Borrego Solar and Geostellar.

\section{D2 - Avoided Cost Constrained}

As stated in the Deliverable Table above, the goal of the second deliverable for the Avoided Cost Solution was to deliver a Beta release version with better avoided cost calculations including dynamic profiles built from customer bills, net metering constraints, and likely tariff considerations. Additionally, we were to secure beta customers actively using these features.

The capabilities added in "D2 Avoided Cost - Constrained" were:

1. Bill-solve for dynamic load profiles using monthly bill costs and the best fitting baseline usage data

2. Selecting baseline / typical usage from an additional three states (New Jersey, Illinois and New York) as well as California 
3. Avoided Cost of Solar - Constrained improved calculations by:

3.1.Better estimating usage using dynamic profiles

3.2. Incorporating net metering constraints

3.3. Easily identifying optimal (lowest cost) tariff that is available

3.4. Integrating PVWatts solar production modeling software

4. Displaying all of the above within the calculation results

Genability also had a number of solar parties express interest in seeing functionality as it was developed. In addition to the beta customers, Genability had collaborative discussions with several other SunShot partners including Clean Energy Experts, Urban Glue, EnergySage and Tigo Energy.

\section{D3 - Avoided Cost Constrained}

As stated in the Deliverable Table above, the D3 Deliverable marked a shift in focus from features to customer usage in preparation for D4's Public Beta Commercial launch. With D3, Genability delivered Version 0.8 of the Avoided Cost Solution including solar rate plans, multiyear solar savings including escalators, opportunity management, baselines for 20 new states and additional 3rd party software integrations. Our customers were currently integrating these features into their business processes and their feedback is driving the refinements needed to prepare the Avoided Cost Solution for Public (Beta) Launch in May.

The capabilities added in "D3 Avoided Cost - Optimized" were:

1. Avoided Cost of Solar - Constrained improved calculations by:

1.1. Incorporating PPA rates to calculate the full solar savings equation

1.2. Incorporating cost escalation assumptions • Incorporating system degradation rates

1.3. Support for all of these factors over contract periods of up to 30 years

1.4. Displaying all of the above in calculation results and graphs that display savings over time.

1.5. Customers can build, store and use solar rate plans for use in Avoided Cost Calculations

2. Select baseline / typical usage from an additional 20 states (Arizona, Colorado, Connecticut, Delaware, Florida, Hawaii, Maryland, Massachusetts, Minnesota, Nevada, New Mexico, North Carolina, Oregon, Pennsylvania, Tennessee, Texas, Vermont, Washington, Washington DC, Wisconsin) as well as California, New Jersey, New York and Illinois.

3. Solar production data accepted via flexible CSV format and native format of two production modeling software packages (PVWatts and PVSyst) as well integration with a popular CRM tool (Salesforce).

Also during the D3 Deliverable, Genability was to secure 6 Beta Customers with at least 20 accounts each. This deliverable was achieved with Borrego Solar, NRG Solar, NRG Residential Solutions, SunEdison, Sunrun and Utility Energy Solutions. We were also to have more than 50,000 Accumulated Avoided Cost Calculations. These deliverable was achieved from ModSolar. 


\section{D4 - Launch}

The D4 Deliverable (Launch) marked the end of our SunShot 6 project and delivered a Public Beta Version of the software and data we have developed over the last 12 months. With D4, the Avoided Cost Solution is available publicly to all solar stakeholders. Details of the Launch are included in the next section.

\section{Product Launch \& Traction}

In May 2013, Genability released the Solar Avoided Cost Solution into Public Beta, making it available to all companies. As part of this release, we developed go-to-market product brands that included verbiage, iconography and new product names. What was called the "Solar Provider Module" above has been launched commercially with the name Genability Solar Savings and the Typicals and Avoided Cost Calculators have been included as "tools" in our newly launched Genability Developer Toolbox.

Since the beginning of the SunShot 6 Project, we have been working with some of the largest residential and commercial solar providers. They have been our Alpha and Beta partners, helped us design, test and refine what we built.

\section{Genability Solar Savings Product Launch}

Genability Solar Savings was officially launched in May 2013. Genability Solar Savings enables solar providers and developers to understand and maximize their customers' potential savings with solar. Solar Savings provides the answers to analyze RFPs, quantify and assess leads, deliver quicker proposals, close more deals, provide post-install savings reports and increase referrals. Genability Solar Savings is ideal for residential and commercial solar developers and installers, as well as financiers, hosts and 3rd party solar stakeholders.

The launch of Genability Solar Savings included an updated website, a targeted sales campaign and an article in Solar Industry Magazine.

Some of our commercial solar customers now include NRG Solar, Borrego Solar, SunPower, SunEdison, SoCore Energy, REC Solar and SOLON.

Two of our residential solar customers are Sunrun and NRG Residential Solar Solutions.

\section{Genability Developer Toolbox Product Launch}

The Developer Toolbox is for solar companies that have their own technology platforms and would like to include one or more of our solar features or tools. The two main tools developed as part of our SunShot 6 project are Genability Typicals and our Genability Solar Savings Calculator.

The Developer Toolbox was launched in May 2013 and included an updated website and blog post. Some of our Developer Toolbox customers include ModSolar, SolarList and Geostellar. 


\section{Media Attention \& Marketing Events}

During the SunShot 6 project, Genability participated in numerous marketing and industry events, and received media coverage. Below is a chronological summary of the marketing efforts and media coverage.

Department of Energy SunShot Conference. June 2012. Genability traveled to Denver, Colorado in June 2012 to attend the Department of Energy SunShot Conference, announce the SunShot 6 award and meet other SunShot awardees.

Greentech Media Article. June 2012. "Is Software the Solution to Solar Soft Costs?" by Herman Trabish.

InterSolar North America. July 2012. Genability attended the industry conference, met with Beta customers and started marketing the Solar Avoided Cost Solution.

GigaOM Article. July 2012. "Using Electricity Rate Data to Sell Solar". by Ucilia Wang.

"Energy Datapalooza”. October 2012. Jason Riley presented at "Energy Datapalooza” hosted by The White House Office of Science and Technology Policy, Council on Environmental Quality, Department of Energy, and the U.S. Environmental Protection Agency. Jason Riley gave a talk on the power of open data.

VERGE Accelerate. November 2012. Jason Riley was presented at VERGE Accelerate, a halfday event in San Francisco that brought together top VC investors and cleantech startups focused on energy and transportation technologies. Jason had 3 minutes to answer (i) why do you do what you do, (ii) what market / problem do you go after, and (iii) how do you do it? Video of Jason's speech.

ASES SOLAR. April 2013. Genability was invited by NREL to speak on a panel at the ASES Solar 2013 Conference titled "New Software Tools that Reduce Solar Soft Costs for PV Installers". Other speakers included EnergySage and Concept3D / Simuwatt.

NREL Soft Cost Conference. May 2013. Genability attended Soft Cost meetings at NREL to participate in laying out the soft cost reduction roadmap and key priorities.

Solar Industry Magazine Article. May 2013. Official announcement and launch of Genability Solar Savings.

SunShot Technology Showcase. May 2013 and June 2013. Genability attended the DOE's technology showcase in Oakland and Boston and presented its Solar Savings product suite. 


\section{Appendix I: Features List}

The list below includes all Solar Avoided Cost features added during the Project.

\section{Avoided Cost / Value of Solar Calculations}

1.1. Utility Solar Savings Calculation that reproduces the customer's post-solar utility bill

1.2. Convert utility usage into annual-hourly data

1.3. Convert solar production into annual-hourly data

1.4. Dynamically create post-solar usage by subtracting solar production from utility usage

1.5. Run post-solar usage through tariff engine to calculate post solar bill

1.6. Total Solar Savings includes the price of solar in the savings analysis, deliver analysis in 1 year and 20 year views

1.7. Assign pricing rules (solar tariff) to the solar production. Per kWh price for a PPA or a fixed price for a lease

1.8. Calculate the solar cost of the solar solar system using the solar tariff

1.9. Calculate first year solar savings by subtracting both the solar cost and the postsolar utility cost from pre-solar utility costs

1.10.Project the first year solar savings forward 20 years by applying a solar degradation rate (reducing solar production over time), utility rate escalator (increasing the price of electricity bought from the utility over time) and PPA/Lease escalator (increasing the price of electricity from the solar system over time)

\section{Typical Costs}

2.1. Built Typical data models utilizing DOE CRBs, EnergyPlus, RECS, CBECS, and utility data

2.2. Created an annual hourly (8760) master Typicals curve for specific customer types (Residential, Commercial)

2.3. Built algorithms that transform the master Typical into a utility/climate zone Typical using utility-specific usage data creating an 8760 profile for each tariff in our database.

2.4. Calculated rates and costs for the tariff-specific 8760 recording rates and costs at the interval level.

2.5. Built Web Interface that allows users to find and explore the Typical data. Includes the ability to download the raw data in a CSV or dynamically search the data (e.g. Find the highest priced hour in July).

2.6. Built Map interface that allows users to find and explorer Typical data through a map.

\section{Solar Payment Terms}

3.1. Added ability to create private solar tariffs, including:

3.1.1.Cents per kWh rates (PPA Rates)

3.1.2.Dollars per Mo rates (Lease Rates)

3.1.3.Any combination of multiple PPA and lease rates

3.2. Added solar offer module to the rate engine to calculate solar bill

3.3. Incorporated solar tariff calculations in savings analysis

\section{Net Metering}

4.1. Built data model to accommodate the variety of net metering rules available in the U.S.

4.2. Collected net metering rules nationwide

4.3. Added net metering flag to all eligible rates 
4.4. Added net metering algorithm to the rate engine

5.Tariff Comparison / Optimization

5.1. Collected and made available for search the tariff eligibility rules (e.g. min and/or max demand to be eligible for a tariff)

5.2. Tariff Comparison feature in Explorer allows customer's to evaluate a scenario under all available tariffs

5.3. Added Factor feature to cost analysis that allows the user to increase or reduce solar production in a solar savings calculation by applying a factor (e.g. 2 doubles solar production). This allows the user to quickly determine optimal solar system size.

6.Escalators and Multi-Year Calculations

6.1. Added data format to the rate engine output to multi-year cost series (Value of Solar API)

6.2. Implemented Utility Rate Escalation into multi-year calculations

6.3. Implemented PPA/Lease Escalation into multi-year calculation

6.4. Implemented Solar Degradation rates into multi-year calculations

7.BillSolving

7.1. Built bill-solve capability that begins with a dollar amount and derives the number of kWh hours the customer used., using the typical usage data for the customer's tariff. This allows usage to be determined from a dollar amount rather than $\mathrm{kWh}$.

8.0pportunity Management

8.1. Added the account owner to the account

8.2. Incorporated Salesforce lead id into Value of Solar API as an additional option.

8.3. Added account status

8.4. Added account type

8.5. Added Search-ability on Account Owner, status and type

9.Software Integrations

9.1. Integrated PWWatts into Explorer

9.2. Imported weather station and solar irradiance data for use with PV Watts integration

9.3. Added support for PVSyst Production output in its native format

9.4. Added support for Salesforce CRM Tools

9.5. Built Excel Add-in that allows the user to search for tariffs and pulls typical usage and costs back into Excel 